\title{
Sociologia da juventude - olhares interdisciplinares e intertemáticos.
}

Silvia Fernandes ${ }^{1}$

Resumo: 0 texto apresenta o dossiê sobre Sociologia da Juventude, além de realizar um breve balanço dos estudos que articulam juventude e religião no país. $\mathrm{O}$ objetivo é apresentar a relevância da abordagem sociológica no tema que, longe de considerar a juventude como uma categoria que se esgota em si mesma, busca delinear analiticamente interfaces profícuas. $\mathrm{O}$ esforço dos autores cujos textos integram o dossiê foi trazer ao debate público resultados de suas pesquisas. Estas assumem a juventude como um lugar de análise fértil nos processos de mutação social em diferentes contextos locais e transnacionais.

Palavras-chave: sociologia da juventude, política, cultura, mudança social, gênero.

Sociology of youth - interdisciplinary and inter-thematic views.

Abstract: The paper presents the dossier on Sociology of Youth and, in addition, provides a brief review of the studies that articulate youth and religion in the country. The proposal is to present the relevance of sociological approach in the theme that, far from considering youth as a category that exhausts itself, seeks to delineate analytically useful interfaces. The effort of the authors whose papers are part of the dossier was to bring to the public debate outcomes of their researches.

1 Programa de Pós-Graduação em Ciências Sociais da Universidade Federal Rural do Rio de Janeiro (UFRRJ) - Seropédica/Nova Iguaçu - Brasil - fernandes.silv@gmail.com 
Those papers take on youth as an issue of fertile analysis in the processes of social change in different national and transnational contexts.

Key words: sociology of youth, politics, culture, social change, gender.

\section{A juventude e seus desafios interpretativos}

Assim como toda categoria sociológica, a juventude é polissêmica. Os múltiplos sentidos a ela atribuídos são expressos nas diferentes dimensões da vida social e atravessados pelas transformações conjunturais de uma dada sociedade. Dito de outro modo, os sentidos dados à juventude e os que por ela são incorporados levam em conta os loci em que os jovens estão situados e o contexto sociocultural, econômico e político em que estão inseridos, além de suas próprias trajetórias.

Destarte, a realidade global apreendida e compartilhada por eles contribui na formação de suas identidades de gênero, política, religiosa, dentre outras, e nas cosmovisões que compartilham com seus pares geracionais.

Compreendida como um segmento em constante mutação, a juventude é intrinsecamente plural, sendo dispensável, portanto, a agregação do "s" em sua grafia (Fernandes, 2018). Afirmamos que múltiplas lentes de sentido podem ser acopladas a esta categoria tão convocada e disputada nos tempos atuais, o que torna o presente dossiê oportuno, considerando principalmente o cenário de céleres transformações que se espraia na sociedade contemporânea.

Com efeito, no Brasil, mudança e mutação parecem adquirir diferentes conotações. Especialmente a partir do pleito presidencial de 2018, constatou-se que a polarização política e os discursos intransigentes adquiriram características inusitadas, mobilizando a população adulta e os jovens de diferentes estratos sociais em prol de suas crenças, valores e expectativas de sociedade. De um lado e de outro dessa polarização estava em jogo a ideia de mudança que não tem sido suficientemente problematizada. Enquanto sociologicamente o termo mudança sugere alteração de um estado de coisas a outro e o ponto de chegada tende a ser visto numa perspectiva positiva, o conceito de mutação reivindica processo, volubilidade, caminho em curvas, recomeços, em que as transformações perpassam modus vivendi e mentalidades, mas não podem ser consideradas acabadas.

Parto deste eixo para apresentar o dossiê em tela. As análises com pretensão de longa duração tenderão a fracassar, especialmente no universo juvenil, em que as mutações sinalizam para o que Jesús Martín-Barbero chamou de 
"mudança profunda dos modelos de socialização" (Mártin-Barbero, 2006: 41). Para o autor, as ditas mudanças se inscrevem desde o padrão de conduta dos jovens - que deixam de ter os pais como referência mandatória - até a cultura, que dispensa o livro como seu principal mediador, isto é, o acesso à informação e ao conhecimento ultrapassa de modo mais intenso as narrativas escritas.

Pode-se considerar, portanto, que mutações contemporâneas no universo juvenil estão intrinsecamente relacionadas com as distintas formas de acesso à informação - que têm se dado, sobretudo, por meio das novas tecnologias e seus atrativos digitais. Essa nova linguagem se constitui como um elemento desafiador para se desenlear a natureza das transformações ou mutações das sociedades globais e suas consequências no multifacetado universo juvenil.

Até o início dos anos 2000, podemos afirmar que as perspectivas analíticas sobre a juventude oscilaram entre a ênfase no conflito, crises e excessos inerentes à condição juvenil, e a ênfase no caráter narcísico, individualista ou disfuncional dos jovens (Gonçalves, 2005; Sposito; Carrano, 2003). Mas o advento das novas tecnologias e o acesso das populações jovens a esses meios tornou mandatório que se empreenda o que eu chamo de giro analítico. Desta forma, qualquer que seja o ângulo sob o qual se estuda a juventude, torna-se necessário sublinhar o quanto os jovens estão mergulhados em teias de sentido capitaneadas pela nova fase da globalização cultural, que traz em seu bojo o avanço das novas tecnologias e mídias digitais como elementos que compõem suas identidades.

Com efeito, o excesso de linguagens, símbolos, imagens e visões de mundo que os jovens produzem, absorvem e/ou reproduzem em ambientes virtuais tem impactos em suas relações sociais e ganham novos contornos na abordagem contemporânea sobre saberes, conhecimento e cognição das novas gerações.

Levando-se em conta o elemento heterogêneo, a juventude pode ser pensada como um ator que (des)orienta a vida social com base no quanto catalisa, rejeita ou contesta os anseios de uma sociedade mais ampla. O segmento passa a ser objeto de olhares interdisciplinares e inter-temáticos por ser exatamente nele que os indivíduos tendem a projetar expectativas de futuro tendo como referência a ideia de progresso, desenvolvimento ou processo civilizatório.

Tomando-se o caso brasileiro, há algumas décadas os jovens deixaram de ser analisados apenas pela ótica geracional ou pelas implicações oriundas de sua passagem para o universo adulto e vêm sendo pesquisados de maneira interdisciplinar, considerando-se sua atuação como atores políticos, religiosos ou dinamizadores da cultura. Além disso, muitos estudos colocaram em destaque a situação de vulnerabilidade juvenil, chamando atenção para o que pode ser visto como um protagonismo negativo (Santos; Yamamoto, 2018). Nessas 
abordagens, o foco paira sobre o cenário que produz uma juventude inativa no mercado de trabalho, excluída das salas de aula, violentada em seus direitos, exposta a distintas formas de violência.

Por seu turno, várias pesquisas (Novaes, 2011; 2012; Pais, 2006; Abramo; Branco, 2005; Fernandes, 2010) abordaram as subjetividades e a capacidade dos jovens de transformarem seus espaços de vida com base em iniciativas culturais e ações socioeducativas. Essas dinâmicas os reposicionam na vida social, retirando-os do lugar de receptores de políticas públicas para o de sujeitos, cuja identidade é formada levando-se em conta ingredientes diversos, encontros, invenções, formação de redes que extrapolam seus próprios territórios.

Cumpre, contudo, não romantizar a juventude. A depender de um conjunto de fatores nem sempre mensuráveis, o jovem contemporâneo pode também gerar e/ou reproduzir práticas que corrompem e ameaçam a estrutura social. Como exemplo, menciono os skinheads dissidentes do movimento originário na Inglaterra dos anos de 1960. O ódio aos imigrantes e as práticas extremistas fazem dos skinheads um grupo que ilustra percursos juvenis socialmente condenáveis. As condutas radicais oriundas de determinados jovens espraiam-se em distintas sociedades e podem alterar a cena pública em direções impensadas.

No Brasil, com as transformações no cenário político da última década e mais acentuadamente com as Jornadas de junho de 2013, a manifestação pública dos segmentos juvenis têm assumido novos contornos. Os jovens têm se mostrado mais ativos na reivindicação de direitos e na contestação do status $q u o$, optando pelo esvaziamento da prática política institucional e pela rejeição ao jogo partidário.

Para Esther Solano (2017), o sentimento de negação política das Jornadas de junho se estendeu para os anos subsequentes e resultou em um país cada vez mais polarizado. Note-se, contudo, que no tocante à polarização, a juventude compõe este quadro, mas não o esgota, uma vez que a complexidade do jogo político na atual conjuntura brasileira não resulta apenas na divisão da sociedade, mas, sobretudo, nas nuances discursivas que cada vertente político-ideológica aciona, ainda que haja linhas de ação e pensamento comuns em ambos os lados. Dito de outro modo, no jogo das tendências político-ideológicas há um conjunto de nuances em que meramente a ideia de polarização não permite ampliar os matizes e nem traduz o campo de tensões e disputas que recheiam essas vertentes.

Extrapolando o universo da política e do lugar social da juventude, entendo que o olhar que propõe a ampliação de variáveis capazes de traçar um perfil mais adensado do jovem na atualidade se configura como uma postura analítica 
bem-vinda. Isto pressupõe não encerrar o quadro analítico a respeito dos jovens exclusivamente nos eixos até aqui discutidos, mas abrir-se aos campos que os atraem e mobilizam para além daqueles classicamente abordados. A religião se apresenta como um desses campos potencialmente relevantes na compreensão da juventude e suas condutas.

\section{Religião e juventude - o campo em construção}

Durante décadas a sociologia da juventude ocupou-se em analisar o jovem como sujeito principal nos processos de mutação da sociedade, articulando, particularmente, as chaves da política e da vulnerabilidade social. A pergunta que se coloca é: haveria, na atualidade, novas esferas sociais a serem agregadas aos eixos interpretativos quando o tema é a juventude? Entendo que a resposta a esta questão é positiva e que a religião vem expandindo sua centralidade no tecido social, ainda que tenha permanecido em um ostracismo analítico nas décadas anteriores. As razões para tal ostracismo precisariam ser pesquisadas. Contudo, poder-se-ia levantar a hipótese de que, como os estudos sobre mudança social tenderam a adotar a perspectiva marxista, a religião figurava como uma realidade liminar, considerada menos relevante na compreensão dos segmentos juvenis. Neste caso, a ideia de protagonismo juvenil como chave para a construção do futuro não comportava o elemento religioso.

Com a consolidação do pluralismo religioso no Brasil e na América Latina a partir dos anos de 1990, não seria recomendável ignorar o impacto das cosmovisões religiosas nas condutas juvenis sob risco de se obliterar uma lente epistemológica profícua.

Considere-se, portanto, que as igrejas e espaços religiosos passaram a atrair os jovens constituindo-se como uma das principais formas de agremiação, uma vez que associações sindicais e partidos políticos estariam atravessando uma perda de credibilidade aguda. Sendo assim, algumas denominações pentecostais, como a Assembleia de Deus, têm estimulado os jovens a concluir os estudos; a buscar alternativas laborais e ainda a produzirem cultura e arte por meio da música, de grupos de teatro amador e outras iniciativas dessa natureza que emergem baseadas nessa comunidade religiosa (Fernandes, 2011).

Destarte, as mutações do campo religioso brasileiro provocaram as ciências sociais a empenhar esforços na compreensão das ofertas de sentido que as instituições religiosas disponibilizavam aos jovens. Do mesmo modo, era importante perceber os sentidos que eles próprios atribuíam à sua adesão ou rejeição religiosa. Nesta direção, cabe destacar os estudos de Cecília Mariz (2005), 
Regina Novaes (2012; 2011), Sílvia Fernandes (2018; 2018a; 2011; 2010), Fátima Tavares e Marcelo Camurça (2006), Solange Rodrigues (2012), Flavio Sofiati (2012), dentre outros. Estava em jogo a compreensão das mutações juvenis na atualidade e das possibilidades de pensar a juventude considerando suas escolhas religiosas ou pela formulação crítica que os jovens fazem a esta esfera. Emergia, assim, a possibilidade de articulação entre dois campos profícuos na sociologia: a juventude e a religião.

Esses pesquisadores e pesquisadoras passam a se debruçar sobre as idiossincrasias das escolhas juvenis no terreno da religião, analisando fatores e expressões que alteram a vida dos jovens oriundos de contextos sociais diversos. O mapeamento das expressões religiosas juvenis inclui naturalmente as esferas pública e familiar permitindo um sem número de possibilidades analíticas.

Constatou-se, em alguns desses estudos, que a adesão religiosa reinscrevia determinados jovens nas configurações familiares; impulsionavam suas escolhas no campo profissional (Fernandes, 2011; 2014); dinamizavam seus processos de sociabilidade na medida em que as igrejas funcionavam como espaços de encontro e construção de novos amigos (Magalhães, 2018); alteravam a vida das cidades e periferias urbanas, fomentando a cultura e a dinâmica dos chamados coletivos urbanos.

Não obstante, é fato que determinados setores juvenis podem se apropriar de lugares de poder para, com base neles, produzir "efeitos de verdade" (Foucault, 2006:179), ditar comportamentos a toda a sociedade e assumir o fundamentalismo religioso como premissa.

Um caso que merece atenção é o movimento chamado Radicais Livres, fundado por Naor Pedroza, no ano de 1997. A frase de abertura no website do movimento expressa a intenção das lideranças: "Queremos a transformação completa da vida e destino de jovens" ${ }^{\prime 2}$.

O Movimento Radicais Livres, cujo ethos religioso é neopentecostal, atrai jovens de diferentes camadas sociais. A ação desses jovens extrapola a dimensão de igreja, espalhando-se em ambientes universitários, tendência presente em outros movimentos revivalistas baseados na emotividade e intimismo (Sofiati, 2012). Os Radicais Livres advogam ainda uma ideia de "governo da nação" que os coloca no limiar da política de caráter dominador, no sentido weberiano. Tem-se, então, um tipo de dominação carismática em que os seguidores do líder agem pela relação afetiva, baseada na confiança, na "veneração extracotidiana

2 Confira no website do movimento: <http://radicaislivres.com/movimento-radicais-livres/>. Acesso em: 16 set. 2019. 
da santidade, do poder heroico ou do caráter exemplar de uma pessoa e das ordens por esta reveladas ou criadas" (Weber, 1998: 141).

No website dos Radicais Livres é descrito o objetivo do líder fundador:

Edificar uma geração de líderes e de pastores, que assumirão o comando, o governo desta nação, a fim de afetar, na prática, os pilares do Brasil. Uma Geração Radical, que hoje anda na contramão do mundo e que fará a diferença quando assumirem lugares importantes no país 3 .

Cumprindo a proposta de expansão, no ano de 2016, um ano antes de completar 10 anos, o Movimento Radicais Livres iniciou o projeto junto a escolas e universidades, espaços de intensa e plural presença juvenil. Sua narrativa pode produzir extremismos de natureza política e religiosa, num discurso cujo teor pode ser autoritário, mas revestir-se de sacralidade. Tais condutas tendem a fragilizar a coesão social na medida em que ameaçam a liberdade individual e produzem coletividades com ações moralmente questionáveis. $\mathrm{O}$ discurso dessas lideranças religiosas oscila entre a negação da alteridade e o incremento de condutas religiosas dominadoras. Estas podem pautar as práticas e as relações sociais e políticas dos jovens que a elas aderem.

Ressalta-se, com base no debate circunscrito nesta seção, que a articulação entre religião e juventude pode e deve ser mais explorada pelas ciências sociais. O cenário sociopolítico que o Brasil atravessa tem como fator relevante a presença da religião no espaço público, cuja presença juvenil é premente e tem, de certo modo, rearranjado o jogo democrático no país e na América Latina4.

\section{A pluralidade juvenil no dossiê}

O conjunto de textos articulados no presente dossiê vem, portanto, somar-se aos vários esforços já empreendidos em busca de se compreender as especificidades da juventude 5 , sobretudo pela configuração do cenário sociopolítico e cultural desafiador que a sociedade brasileira atravessa.

3 Confira no website do movimento: <http://radicaislivres.com/movimento-radicais-livres/>. Acesso em: 16 set. 2019.

4 Para um trabalho interessante sobre a atuação política de jovens evangélicos na política argentina, confira o estudo de Mariela Mosqueira (2015). A autora apresenta a atuação de jovens evangélicos do grupo denominado "valores para meu país" com intensa atuação na esfera pública, especialmente no que se refere aos temas da moral sexual.

5 Importa trazer a referência do dossiê sobre Juventude organizado por Martins e Augusto (2005), na Revista Tempo Social, além da resenha sobre a tematização da juventude nas Ciências Sociais que resume os trabalhos de autores de referência nos estudos sobre o tema (Pereira, 2005). 
$\mathrm{Na}$ esteira de estudos que avaliam a relação de jovens universitários com a política, o artigo de Cristina Satiê e Frank Mezzono apresenta resultados de pesquisas qualitativas com jovens estudantes na Universidade Estadual do $\mathrm{Pa}$ raná - UNESPAR.

Os autores traçam uma breve contextualização do cenário político no país e no estado do Paraná para então justificar a escolha do objeto. As narrativas de quatorze jovens são analisadas em busca das representações que constroem sobre a política. Os autores delineiam quadros em que são comparadas as interpretações sobre as categorias sociológicas com os discursos dos jovens. Sublinha-se-se que a ideia de política associada à corrupção, "espaço de debate", conhecimento e cotidiano ilustram como tal conceito adquire novos contornos tendo em vista a perspectiva dos jovens universitários.

A abordagem transnacional aparece em dois trabalhos do presente dossiê. Antonio Braga se debruça sobre os jovens brasileiros de "segunda geração" residentes nos EUA. Resultado de um investimento antropológico, a pesquisa de Antonio Braga mostra a complexidade do processo de sociabilidade e formação de identidades juvenis em contexto transnacional. $\mathrm{O}$ artigo faz uma importante contextualização histórica sobre a presença dos brasileiros nos EUA e mostra como "estar entre dois mundos" faz parte da subjetividade dos jovens filhos de imigrantes brasileiros. Com base em seu texto é possível pensar as tensões inerentes ao ato de pertencer ampliando as possibilidades de interpretação do próprio conceito de nação.

Por sua vez, o artigo de Wanjiru Gitau analisa como a juventude sul-africana potencializa as transformações do continente, seja por meio do ativismo cultural, seja por meio do ativismo político e pelo vigor na inovação de atividades econômicas. A autora traz uma densa explanação histórica sobre o continente africano, revelando ao leitor as tensões e avanços políticos de um cenário pouco explorado e conhecido pelos cientistas sociais. Wanjiru Gitau problematiza a visão corrente da academia que tende a não observar a ascensão da África nas últimas décadas e demonstra - ancorado em dados demográficos e socioeconômicos sólidos -, como vem se dando tal processo de emancipação do continente. A autora mostra como os jovens adultos protagonizam essa emancipação e como o ativismo cultural e político juvenil se constitui, por exemplo, entre os grafiteiros no Quênia, que expõem os rostos dos políticos corruptos nos murais das cidades. Por sua vez, a religião impulsionou o ativismo político na República Centro Africana, com base na ação dos jovens escoteiros que se organizam para levar a educação a outros jovens. 
Voltando ao cenário brasileiro, o trabalho de Marcelo Senna possui pontos de contato com o estudo de Gitau, na medida em que trabalha com o protagonismo juvenil na formação de coletivos urbanos aptos na articulação entre cultura e política. $\mathrm{O}$ autor utiliza a metodologia de estudo de caso estendido proposta por Michael Burawoy (1998), combinando ciência reflexiva com etnografia. O trabalho traz uma importante contribuição para o entendimento das dinâmicas entre políticas culturais, ações juvenis e periferia urbana e lança uma hipótese madura a respeito do tema. Para o autor, a heteronomia presente no desenvolvimento das políticas públicas e culturais cria empecilhos no processo de formulação de políticas adequadas por parte do Estado. Em muitos casos, ocorre absoluto descompasso entre as necessidades locais e as proposições do Estado. Assim, a cosmovisão que norteia o incremento de políticas para a juventude tende a considerar os jovens em sua situação de vulnerabilidade social, ignorando suas vivências e potenciais.

Em uma perspectiva de valorização do gênero feminino, o artigo de Luiz Rios e Marion Quadros acena para uma temática clássica nos estudos sobre juventude: o dilema do exercício da sexualidade e reprodução entre jovens mulheres adolescentes. Com base nos resultados de pesquisas realizadas ao longo de seis anos, o artigo problematiza a chamada "gravidez na adolescência”, afirmando que os estudiosos do fenômeno tendem a não levar em conta os significados que a iniciação sexual traz para as mulheres. Trata-se de uma valiosa contribuição para a sociologia da juventude por olhar de frente o "pânico moral" presente na sociedade ao se deparar com esse contingente demográfico feminino. A pesquisa traz achados etnográficos preciosos, como o fato de que as mães conversam pouco sobre sexualidade com suas filhas visando a não estimular a prática sexual, por exemplo, o que acaba tendo um efeito reverso. Por fim, os autores ampliam o debate trazendo o "percurso reprodutivo de mulheres adultas".

Com esse conjunto de textos, temos a expectativa de oferecer uma efetiva contribuição ao debate sobre sociologia da juventude, visto que em todos os trabalhos aqui apresentados há questões instigantes que, certamente, inspirarão pesquisas futuras sobre este clássico tema.

\section{Referências}

ABRAMO, Helena; BRANCO, Pedro Paulo Martoni. (Orgs.). Retratos da Juventude Brasileira. Análises de uma pesquisa nacional. São Paulo, Instituto Cidadania, Fundação Perseu Abramo, 2005. 
BURAWOY, Michael. The Extended Case Method. In: Sociological Theory, v. 16, n. 1, 1998.

DIAS, Adriana Abreu Magalhães. Observando o ódio: entre uma etnografia do neonazismo e a biografia de David Lane. - Campinas, SP: Tese apresentada no Instituto de Filosofia e Ciências Humanas - IFCH [s.n.] 2018. Disponível em: <http://repositorio. unicamp.br/jspui/handle/REPOSIP/332688>. Acesso em: 16 set. 2019.

FERNANDES, Silvia Regina Alves. Juventude católica e mudança social: limites e possibilidades. LELLIS, Nelson e PY, Fabio. (Orgs.) Religião e Política à Brasileira. Ensaios, Interpretações e resistência no país da política e da religião. São Paulo, Edições Terceira Via, 2018, pp. 63-70.

Trajetórias religiosas de jovens sem religião - algumas implicações para o debate sobre desinstitucionalização. Interseções, v. 20, n. 2, Rio de Janeiro: UERJ, 2018a, pp. 369-387.

Religiosidades, trânsitos e permanências no século XXI - particularidades das novas gerações. In: PANASIEWICZ, Roberlei; VITORIO, Jaldemir (orgs). Espiritualidade e Dinâmicas Sociais - memória - prospectivas. São Paulo, Paulinas; Belo Horizonte: SOTER, 2014, pp. 81-109.

. Marcos definidores da condição juvenil para católicos e pentecostais na Baixada Fluminense - algumas proposições a partir de um survey”. Religião \& Sociedade (Impresso), v. 31, 2011, pp. 96-125.

. Jovens religiosos e o catolicismo - escolhas, desafios e subjetividades, Quartet/ Faperj, 2010.

FOUCAULT, Michel. Soberania e Disciplina. Microfísica do poder. São Paulo, Paz e Terra, 2006, pp. 179-191.

GONÇALVES, Hebe Signorini. Juventude brasileira, entre a tradição e a modernidade, Tempo Social, Revista de sociologia da USP, v. 17, n. 2, 2005, pp. 207-219.

LEON, Oscar Dávila; SOTO, Felipe Ghiardo. Trayectorias sociales como enfoque para analizar juventudes. Revista Última década, n. 50, 2018. Santiago, Universidade de Chile. pp. 23-39. Disponível em: <https://scielo.conicyt.cl/pdf/udecada/ v26n5o/0718-2236-udecada-26-50-00023.pdf >. Acesso em: 16 set. 2019.

MAGALHÃES, Alexander Soares. Os Jovens e o Pentecostalismo: Considerações sobre a identidade da juventude da igreja Assembleia de Deus a partir um estudo de caso na Baixada Fluminense -RJ. Interseções, v. 20, n. 2, 2018, pp. 268-285 Disponível em: $<$ https://www.e-publicacoes.uerj.br/index.php/intersecoes/article/view/39012>. Acesso em: 16 set. 2019.

MARIZ, Cecilia, L. Comunidades de vida no Espírito Santo: juventude e religião. Tempo Social, São Paulo, USP. Impresso, v. 17, n. 2, 2005, pp. 253-274.

MARTÍN-BARBERO, Jesús. Projetos de modernidade na América Latina. In: Domingues, José Maurício; Maneiro, María (Orgs.). América Latina hoje - conceitos 
e interpretações. Rio de Janeiro, Civilização Brasileira, 2006, pp. 21-51.

MARTINS, Heloisa Helena T. Souza; AUGUSTO, Maria Helena Oliva. Juventude(s) e transições. Tempo Social, Revista de Sociologia da USP, v. 17, n. 2, 2005, pp. 1-4.

MOSQUEIRA, Mariela. "Redimir a política": experiências de militância de jovens evangélicos da Argentina Desidades [online], v. 8, 2015, pp. 9-18 Disponível em: $<$ http://pepsic.bvsalud.org/scielo.php?script=sci_arttext\&pid=S2318-928220150 00300002\&lng=pt\&nrm=iso $>$. Acesso em: 16 set. 2019.

NOVAES, Regina. Juventude, religião e espaço público: exemplos "bons para pensar" tempos e sinais. Religião e Sociedade, v. 32, n. 1, 2012, pp.184-208.

. Reciclagens entre heranças e inovações: juventude, religiosidade e cidadania. In: OLIVEIRA, Pedro A. Ribeiro de; MORI, Geraldo Luiz de (Orgs.). Religião e educação para a cidadania. São Paulo, SP, Paulinas; Belo Horizonte, Soter, 2011.

PAIS, José M. Buscas de si: expressividades e identidades juvenis. In: Culturas jovens: novos mapas do afeto. Rio de Janeiro, Jorge Zahar, 2006, pp. 7-21.

PEREIRA, Alexandre Barbosa. Muitas palavras: a discussão recente sobre juventude nas Ciências Sociais. Ponto Urbe - Revista do Núcleo de Antropologia Urbana da USP, n.1, 30 jul. 2007. Disponível em: <http://journals.openedition.org/pontourbe/1203>. Acesso em: 20 nov. 2019.

RODRIGUES, Solange. Jovens, experiência do sagrado e pertencimento religioso: um olhar sobre a literatura. In: OLIVEIRA, Pedro Ribeiro; DE MORI, Geraldo (orgs.) Mobilidade religiosa, linguagens, juventude, política. São Paulo, Paulinas, 2012, pp. 253-287.

SANTOS, Luana Isabelle Cabral; YAMAMOTO, Oswaldo Hajime. Juventude brasileira em pauta: analisando as conferências e o estatuto da juventude. Revista Latino americana de Ciencias Sociales, Niñez y Juventud, v. 16, n. 2, pp. 657-668. Disponível em: <http:// www.scielo.org.co/pdf/rlcs/v16n2/2027-7679-rlcs-16-02-00657.pdf $>$. Acesso em: 16 set. 2019.

SOFIATI, Flavio. Religião e juventude: os novos carismáticos. 2. ed. São Paulo, Idéias \& Letras / FAPESP, v. 2. v. 2, 2012 (280).

SOLANO, Ester. Em 2013, Avenida Paulista comportou todos, em 2015 foi espaço de polarização. NEXO [online], 2017. Disponível em: <https://www.nexojornal.com. br/expresso/2017/06/17/O-que-foram-afinal-as-Jornadas-de-Junho-de-2013.-E-no-que-elas-deram>. Acesso em: 16 set. 2019.

SPOSITO, Marilia Pontes; CARRANO, Paulo César Rodrigues. Juventude e políticas públicas no Brasil, Revista Brasileira de Educação, São Paulo, v. 24, 2003, pp. 16-39.

TAVARES, Fatima; CAMURÇA, Marcelo. Religião, família e imaginário entre a juventude de Minas Gerais. Ciencias Sociales y Religión, Porto Alegre, v. 08, n. 08, 2006, pp. 07-179.

WEBER, Max. Economia e sociedade: fundamentos da sociologia compreensiva/ Max 
Weber; tradução de Regis Barbosa e Karen Elsabe Barbosa; Revisão técnica de Gabriel Cohn. Brasília, DF, Editora Universidade de Brasília, 1998.

Recebido em: 07/04/2019

Aprovado em: 25/11/2019

\section{Como citar este artigo:}

FERNANDES, Sílvia. Sociologia da juventude - olhares interdisciplinares e intertemáticos. Contemporânea - Revista de Sociologia da UFSCar, v. 9, n. 2, maio - agosto 2019, pp. 339-350. 